\title{
Implementation of a Blended Learning Model in Content- Based EFL Curriculum
}

\author{
https://doi.org/10.3991/ijet.v14i05.8546 \\ Wen $\mathrm{Yu}^{(\varpi)}$ \\ Shenyang Pharmaceutical University, Shenyang, China \\ viweny11@126.com \\ Xiaozhou Du \\ Information and Communication Engineering Design Institute, Shenyang, China
}

\begin{abstract}
Due to the tremendous advancements in technology, blended learning has become a focus in modern higher education which combines the advantages of both online and face-to-face learning. This paper examines the effectiveness of a blended learning model in a content-based EFL curriculum, with a focus of collaborative and independent learning to ensure the achievement of learning outcomes. The evaluation results of a comparative study revealed the efficiency of the present model in which students performed and perceived better. These findings encourage further development of other blended learning options for EFL learning.
\end{abstract}

Keywords - Blended Learning, content-based instruction, computer-assisted language learning, English as a Foreign Language (EFL), pedagogical approach

\section{Introduction}

Blended learning is not a new term, the concept of blending prevails the learning experiences and environments both abroad and domestic. It is the infusion of information technology that endow the term blended learning with a new meaning. In the era of innovative technology, blended learning, harnessing the power of technology and innovative tools to create a more efficient, engaging and learner-centered learning environment is now transforming the way we learn world widely. It is used here to describe an approach in a course design that integrates the best features of traditional face to face and the advantages of online learning.

The goal of this research is to investigate the effective use of a blended learning design in a Content-based EFL Curriculum. Content Based Instruction (CBI) is a global approach in foreign language education. It is highly flexible, as a number of instructional approaches such as cooperative learning, metacognitive learning strategy or extensive reading have been shown to be effective when incorporated into CBI [1]. This study thus aims to find the results to demonstrate the effectiveness of the incorporation of blended learning into CBI to foster language development. This is an important area to explore as promoting English learning in a Content-based EFL Cur- 
riculum involves the following difficulties. Firstly, Students learn English only in the English classes in traditional classrooms, and they have few opportunities to be exposed to English learning environment outside the classroom. Secondly, the targeted freshmen learners have difficulty committing themselves to independent and collaborative learning without support from teachers after class. Therefore, developing an effective language learning environment and learning activities that support English learning without limitation of time and space become a critical issue. There are a few of important questions to examine: what is the impact of the proposed blended learning design on students' actual academic performance in a content-based EFL curriculum? What are the perceptions and learning satisfactions from the students in the process of learning?

\section{Theoretical Background}

\subsection{Blended learning}

Blended learning has many changeable names, such as e-learning [2], hybrid learning [3], technology-mediated instruction [4], web-enhanced instruction [5] and mixedmode instruction [6]. Meanwhile, the definition of blended learning also varies. An early definition of blended learning was described by Bonk and Graham in their book Handbook of Blended Learning as a learning system [7] that combine face-to-face instruction with computer mediated instruction [8], which emphasizes the combination of the best of tradition schooling and the advantages of on-line learning. With the development of new media and improvement of numerous educational technologies and learning tools, the extension of the early definitions is indispensable. As it is suggested by Singh and Reed, "blended learning focuses on optimizing achievement of learning objectives by applying the 'right' learning technologies to match the 'right' personal learning style to transfer the 'right' skills to the 'right' person at the 'right' time" [9]. This paper thus adopts a complete definition from Hoic-Bozic that describes blended learning as "based on various combinations of classical face-to-face lectures, learning over the Internet, and learning supported by technologies, aimed at creating the most efficient learning environment" [8]. It suggests that many factors in a learning system can be blended or integrated, including media and technology, online and traditional face to face learning environment, and instructional approaches. Accordingly, an effective and well-designed blended learning can be an integration or combination of a variety of technologies and pedagogies.

A modern blended learning complies with challenges of modern information communications technology (ICT) include the popularization of wireless communication, social network, and the proficient and frequent online activities of the learners. It should combine mobile learning supported by mobile applications, smart phones, or pad to encourage learners to employ their fragmentary time to study, with which they are able to learn anywhere and anytime. 


\section{$2.2 \quad \mathrm{CBI}$}

CBI is a global approach for foreign language education and its "popularity and wider applicability have increased dramatically since the early 1990s" [10]. Stoller refers CBI as 'an umbrella term', an instructional approach that make a dual, though not necessarily equal commitment to language and content-learning [11]. CBI has been implemented in various ways, content-driven and language-driven curricula are familiar protocols based on different degrees of emphasis placed on language and content. Content driven curricular or immersion programs are prototypical contentbased approach, originally emerged in the Canadian programs in the 1960s in which children were taught traditional school subjects in their second language [12].

Language-driven curricula on the other hand have "a weak content focus" and "stronger commitments to language-learning objectives" [11], thus frequently implemented in EFL courses. These Language-driven curricula are basically theme-based as they are typically designed around themes that intrigue the students. The subject matter of those courses is integrated into individual lessons as a means to help the students develop their language abilities. The content-based EFL curriculum understudy is theme-based. The themes are carefully selected by the teacher and students together from the text materials.

\section{Research Motivation}

The potential of blended learning to enhance the effectiveness and efficiency of learning [13] is quite evident in the previous study. According to Driscoll (2002)[14], blended learning also has a great potential being combined with other pedagogical approaches to produce an optimal learning outcome. Therefore, there is every reason to believe that a blended learning design could be used to facilitate language development in a content-based EFL curriculum. There is an absence of research literature about blended learning in a content-based language course, hence this study aims to evaluate the effectiveness of a blended learning design in a content-based EFL curriculum as stated in the following research questions:

- What is the impact of the proposed blended learning design on students' actual academic performance in a content-based EFL curriculum?

- What are the perceptions and learning satisfactions from the students in the process of learning?

\section{$4 \quad$ Methodology}

\subsection{Blended learning model}

This research aims to evaluate the effectiveness of the blended learning model based on CBI within a foreign language course to improve a learner's language proficiency as shown in Fig.1. 


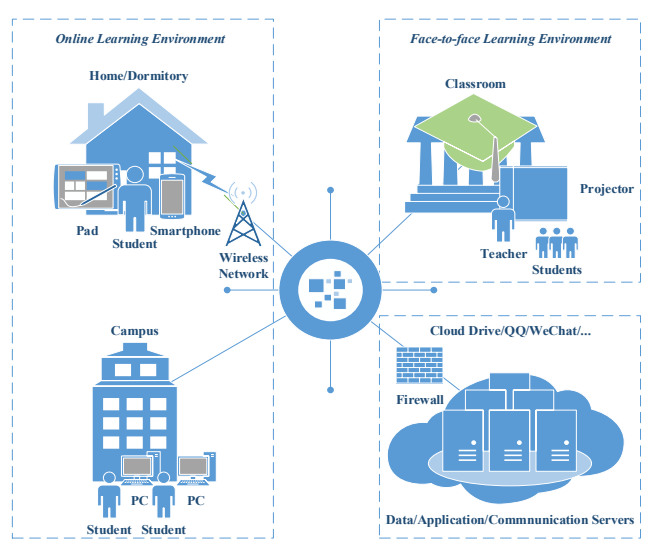

Fig. 1. Blended learning model in content-based EFL learning environment

The course was carefully prepared in the quality of learning materials, organization of both on-line and off-line activities, teaching strategies, and assessment approach. An on-line learning resource library featured by visualization, fragmentization and thematization was built to cater for the need of a content-based course. The resources in the resource library in Fig.2, which include micro lectures, videos and recordings of the latest news items, lectures from TED and celebrities, documentary films, movies, etc., were carefully selected by the teachers and constantly updated.

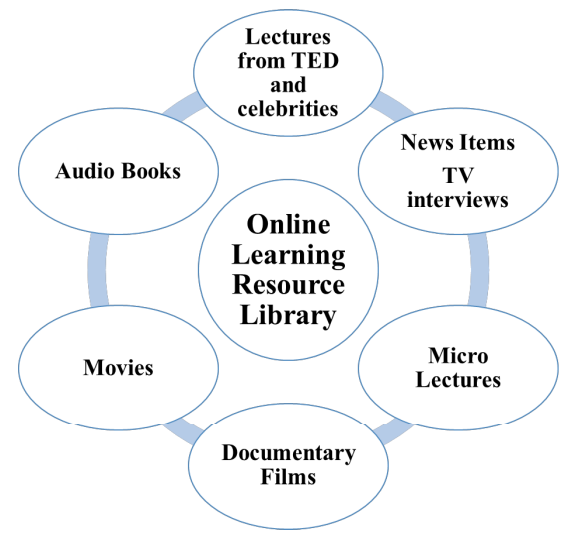

Fig. 2. Types of resources in online learning library

The aim of this task is to establish an immersive learning environment absent in the traditional classroom, where a learner is able to learn anywhere, anytime independently. On-line activities were designed to encourage learners to interact and collaborate with their peers via social network and serve as formative and summative assessment.

This study adopted a mixed methodology (quantitative and qualitative) to do the collection and analysis of data, which allow the researchers "to capture and synthesize data from multiple sources in order to gain more in-depth and comprehensive under- 
standing" [15]. The quantitative assessment focused on intervening experiments using a series of proficiency tests to evaluate the impact of the experiment on the participants' academic performance. The teaching and learning activities in the new model were included in the course of the experimental group. Their performance was statistically analyzed and compared with the control group after the experiment to see whether they managed to achieve the expected learning objectives. In addition, a pretest was conducted on the participants to measure the proficiency level of the participants before the experiment. Data collection mainly included the scores of these tests. A questionnaire with open questions and post-study interviews were performed to investigate the participation, satisfaction and perception of the participants. The questionnaires with 10 open questions were completed by all the participants. 5 interviewed participants were randomly chosen and 10 questions were covered in the interview. The questionaires and transcriptions of interviews were qualitatively analyzed. The following hypothesis was formulated that the implementation of blended learning model in a content-based EFL course helps to improve a learners' language proficiency and well perceived by them.

\subsection{Participants}

The participants were non-English major freshmen in a university. Sixty students majored in pharmacy in the academic year 2015/2016s were randomly assigned to either experimental or control group. The control group, consisted of 30 participants followed the traditional teaching method in their content-based EFL listening and speaking course, while the 30 students in experimental group were instructed by the proposed blended learning design. The students in both groups had spent a semester in the university and their performances in a pre-experiment test were statistically close on both sides. Students' performance at the previous level was usually regarded as the major factor that might affect the evaluation process, thereby it was definite that there was no significant distinction between the two groups.

\subsection{Research progress}

Online learning: In the first phase of the new model application, face-to-face learning was conducted by a cognition of the theme, goal and task as is shown in Fig.3. Students were required to complete their online learning with the vast authentic and theme-based learning materials in the resource library offered by the teacher via a selection of handy learning tools available, whether a laptop, a smart phone or a pad, with which collaborative, interactive and task-based learning were conducted. The teacher selected relevant learning materials from the resource library and shared to the students though Cloud Drive before class. The students were expected to download the learning materials with their smart phones, pad or laptop and complete their tasks anytime and anywhere they would like. A set of interactive APPs were available for oral practice, too. Students were required to interact with APPs from a selection offered by their teacher. 


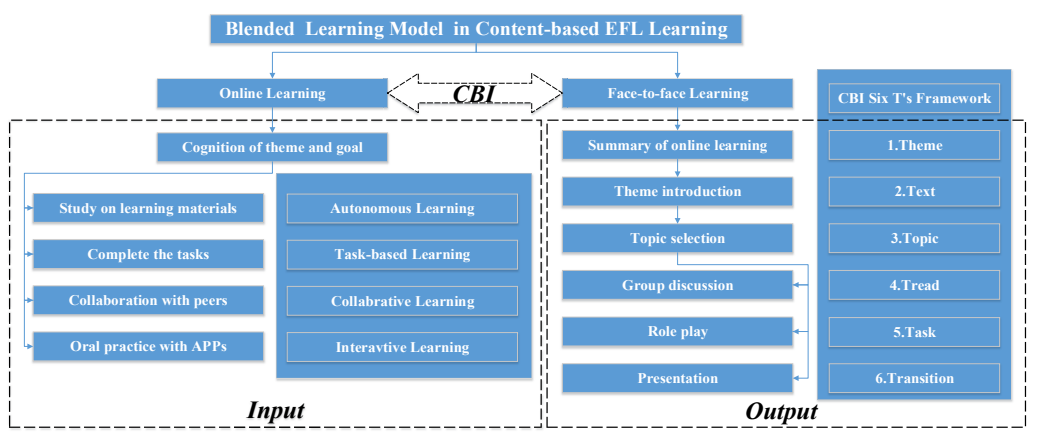

Fig. 3. Activities workflow in the learning module

Besides, students could collaborate via powerful social network, such as instant messaging (IM) like WeChat or QQ, and asked for help anytime from the peers in the WeChat or QQ group as shown in Fig.4. Accordingly, on-line collaboration and peer study were readily accessible with the help of handy mobile learning tools and the wireless network. These on-line learning activities were flexible and intriguing according to the students as the learning materials in the resource library stimulated their motivation and interest.
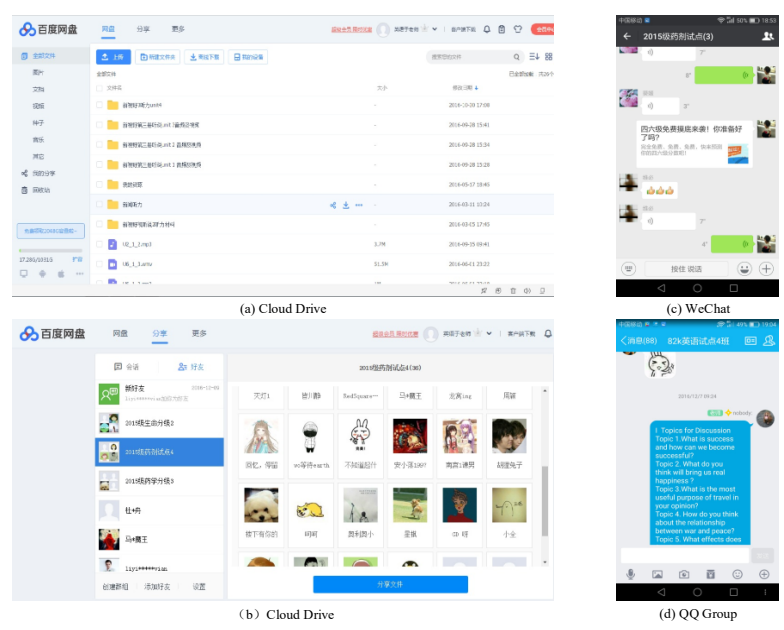

Fig. 4. Online collaborative learning via social network

Face-to-face learning: Fig. 2 shows face to face learning was organized under the instruction of CBI six T's framework [16] which allows the use of themes, topics, texts, tasks, threads, and transitions as criteria in the design and organization to develop a coherent content-based course. The teacher selected a specific theme relevant to on-line learning activities and then assembled appropriate texts to support the theme. Then, the teacher negotiated a set of coherent topics to motivate and interest the students. Tasks were carefully designed to practice language skills and learn content 
information of the texts for the given theme in order to satisfy the student's need and achieve the objectives of the course. Transitions and threads served as additional linkages among topics, texts and tasks throughout the course. To be specific, face to face learning centers on the themes of the on-line learning activities and texts. Students were ensured with enough input by completing their listening assignments online before class and outputted through relevant tasks and class activities in class, such as group discussions, presentations, role-plays.

Above all, the combination of blended learning and CBI effectively enlarged the traditional class with on-line learning environment before class and face-to-face learning in class. The input activities of on-line learning before class and the output activities following CBI six T's framework in class propose a way to work out the problems prevailing in the current EFL course for listening and speaking, such as the limited class hours, the absence of immersive language environment and the deficiency of instructional methods.

\subsection{Experiment internal validity}

Internal validity is the credibility of the causal relationship between variables [17]. When analyzing the causal relationship between independent variable and dependent variable in empirical research, it is necessary to pay attention to eliminating other various confounding variables.

In order to improve experiment internal validity in the study, the following measures (not only but mainly) have been considered:

- Two groups of students had been studying English for a semester in the university before the study, so they had been basically equivalent in cognitive ability.

- Random sampling was used to avoid differences or inequalities in the ability or special aspects of participants.

- Participants did not withdraw during the experiment because they were all students. Thus, the sample size has remained stable.

- Teachers and assistants for two groups of students were carefully selected to ensure their academic level, abilities, experiences, and age were almost similar. This avoids instructor factor becoming a confused variable.

\section{$5 \quad$ Empirical Results}

The study was conducted over one semester for 18 weeks. Students in both the experimental group and the control group participated in the proficiency test, including pre-experiment and post- experiment test. The score of both groups was collected and analyzed. The research team conducted a quantitative analysis of the performance of the experimental group and the control group, using statistical software SPSS22.0 to perform a comparative analysis of the test data. Two kinds of hypothesis were established according to the research problems. Independent sample t-test and paired sample t-test were separately adopted to analyze the score so as to find a significant dis- 
tinction in language proficiency between the two groups of students. There is no violations found in this study. So $p<0.05$ was used as the standard convention level for evaluating statistical significance of all the quantitative analyses.

\subsection{Independent sample test}

The following hypothesizes is proposed in order to find out the changes in the listening and speaking levels of students belonging to experimental group and the control group.

$H_{0}: \mu$ Experimental Group $=\mu$ Control Group

$H_{1:} \mu$ Experimental Group $\neq \mu$ Control Group

$\mu$ is the population mean. $H_{0}$ is a null hypothesis meaning there's no significant difference between means of the experimental group and the control group. On the contrary, $H_{I}$ is an alternative hypothesis meaning there are significant differences between means of two groups. As significant level is set to 0.05 , if $p>0.05 H_{0}$ is accepted and $H_{l}$ is rejected, otherwise $H_{l}$ is accepted and $H_{0}$ is rejected.

Table 1 shows a comparison of the scores of the experimental group and the control group in the pre-experiment test. Independent sample t test results reveal $H_{0}$ is accepted which means there is no statistically significant difference in test scores between the experimental group and the control group $\quad(t=0.065, d f=58, p>0.05)$. The mean indicates a closeness on both sides. Thus, the results show that the two groups had comparable initial conditions before the experiment and it is the basis to guarantee the experiment internal validity.

Table 1. Comparison of pre-experiment proficiency test results *

\begin{tabular}{|c|c|c|c|c|c|c|c|}
\hline & \multirow{2}{*}{\multicolumn{2}{|c|}{$\begin{array}{c}\text { Experimental Group } \\
(n=30)\end{array}$}} & \multirow{2}{*}{\multicolumn{2}{|c|}{$\begin{array}{c}\text { Control Group } \\
(n=30)\end{array}$}} & \multirow{3}{*}{$M D$} & \multirow{3}{*}{$t(d f=58)$} & \multirow{3}{*}{ Sig. } \\
\hline & & & & & & & \\
\hline & $M$ & SD & $M$ & SD & & & \\
\hline LSPT & 57.23 & 7.35 & 57.36 & 8.45 & 0.13 & 0.065 & 0.948 \\
\hline
\end{tabular}

* Statistical parameter description: $n$ is short for sample number, $M$ is short for Mean, $S D$ is short for Std. Deviation, $d f$ is short for Degree of Freedom, MD is short for Mean Difference, Sig. is short for 2-tailed paired t test Significance, LSPT is short for Listening and speaking proficiency test.

After the 18-week experiment, the performance of the students in experimental and control group both enhanced as is shown in Table 2. Independent sample $t$ test results reveal $H_{l}$ is accepted $(t=2.378, d f=58, p<0.05)$. Inspections of the two group means indicate that the average score of the experimental group is significantly higher than the score of the control group. The difference between the means is 3.8 points on a 100-point test. 
Table 2. Comparison of post-experiment proficiency test results

\begin{tabular}{|c|c|c|c|c|c|c|c|}
\hline & \multirow{2}{*}{\multicolumn{2}{|c|}{$\frac{\text { Experimental Group }}{(n=30)}$}} & \multirow{2}{*}{\multicolumn{2}{|c|}{$\begin{array}{c}\text { Control Group } \\
(n=30)\end{array}$}} & \multirow{3}{*}{$M D$} & \multirow{3}{*}{$\begin{array}{c}t(d f=58 \\
)\end{array}$} & \multirow{3}{*}{ Sig. } \\
\hline & & & & & & & \\
\hline & $\mathrm{M}$ & SD & $\bar{M}$ & SD & & & \\
\hline LSPT & 61.43 & 6.69 & 57.63 & 5.64 & 3.80 & 2.378 & 0.021 \\
\hline
\end{tabular}

\subsection{Paired samples test}

Another hypothesizes is proposed in order to find out the changes in the listening and speaking levels of students belonging to experimental group and the control group in pre-experiment test and post-experiment test.

$H_{0}: \mu_{\text {pre }}=\mu_{\text {post }}$

$H_{1:} \mu_{\text {pre }} \neq \mu_{\text {post }}$

$H_{0}$ is a null hypothesis meaning there's no significant difference between means of the group before and after the experiment. On the contrary, $H_{l}$ is an alternative hypothesis meaning there are significant differences.

Table 3 shows that $H_{l}$ is accepted $(t=3.75, d f=29, p<0.05)$ Scores of the experimental group in two tests are significantly varied by the learning strategy used. Matched sample t test results indicate a notable distinction between the scores of the two tests, which demonstrates that the language proficiency of the students in experimental group is notably improved. Apparently, the new instructional mode played a positive role in promoting the listening and speaking proficiency of the experimental group.

Table 3. Comparison of pre and post experiment proficiency test results in experimental group

\begin{tabular}{|l|c|c|c|c|c|c|c|}
\hline & \multicolumn{4}{|c|}{ Experimental Group ( $\boldsymbol{n}=\mathbf{3 0})$} & \multirow{2}{*}{ MD } & \multirow{2}{*}{$(\boldsymbol{d} \boldsymbol{d}=\mathbf{2 9})$} & \multirow{2}{*}{ Sig. } \\
\cline { 2 - 5 } & $\mathrm{M}$ & $\mathrm{SD}$ & $\mathrm{M}$ & $\mathrm{SD}$ & 10.34 & 3.99 & 0.000 \\
\hline LSPT & 57.23 & 7.35 & 61.43 & 6.69 & 10.34 & & \\
\hline
\end{tabular}

Table 4 shows $H_{0}$ is accepted $(t=0.153, d f=29, p>0.05)$. Scores of the control group in the pre-experiment test and the post-experiment test are not significantly noted. Matched sample t-test results indicate no statistical distinction between the score, which demonstrates that the improvement of language proficiency in control group is not notable although a slight improvement is displayed. Apparently, the traditional instruction has exerted slight influence on students' listening and speaking proficiency.

Table 4. Comparison of pre and post experiment proficiency test results in the control group

\begin{tabular}{|l|c|c|c|c|c|c|c|}
\hline & \multicolumn{4}{|c|}{ Control Group ( $\mathbf{n}=\mathbf{3 0})$} & \multirow{2}{*}{ MD } & \multirow{2}{\boldsymbol{t}(\boldsymbol{d}\boldsymbol{d}=\mathbf{29}}{} & \multirow{2}{*}{ Sig. } \\
\cline { 2 - 5 } & $\mathrm{M}$ & $\mathrm{SD}$ & $\mathrm{M}$ & $\mathrm{SD}$ & 0.27 & 0.153 & 0.879 \\
\hline LSPT & 57.36 & 8.45 & 57.63 & 5.64 & 0.27 & \\
\hline
\end{tabular}




\section{Discussion}

The first research question was "what is the impact of the proposed blended learning design on students' actual academic performance in a content-based EFL curriculum?" As shown in Table 2, the average grade on assessment of the experimental group exceeded that of the control group in the post-test. The hypothesis was accepted that students from experimental group achieved significantly better academic performance. One explanation can be accounted for this result. Blended learning design built an effective on-line environment that broke the limitation of time and space in the traditional classroom. It actually enlarged the traditional classroom in time and space so that the students were allowed to commit independent learning in an immersive learning environment with vast materials and learning content carefully selected by teachers with handy tools, mostly their smartphones outside the classroom. A connection therefore was built between on-line study and face to face meeting, which helped to maintain the unity of the course. The content-based EFL listening and speaking course thus divided into two unified parts, on-line practice and off-line speaking practice. The students could do listening practice on the internet anytime and anywhere with the help and assistance from teacher and peers through social network. In the traditional classroom, the teacher solved their problems in their independent learning in person and organized class activities and oral practice based on their previous online listening practice. The learning outcome was much better in an organized on-line learning environment than a disorganized, randomly conducted on-line learning based on a teacher-observation as their working hours, homework submission, problems in the process of learning were all in the mastery of the teacher. In addition, more efficient traditional classroom was established as both the teacher and students could focus on enriched class activities denied by the traditional listening and speaking class. The study also found that the students in the experimental group are much more confident and eloquent in the oral exam of the posttest, therefore a higher level of oral skills are expected in a long-term study.

The second research question is "what are the perceptions and learning satisfactions from the students in the process of learning?" The questionnaire and interview proved that the blended learning design resulted in an increase of students' engagement and satisfaction. They are willing to participate in these learning activities with familiar handy tools such as smartphones and pads, which are much more flexible and intriguing than traditional class activities. An interviewee indicated that the research model set a good example on students about how to practice listening and speaking on the internet on their own outside the classroom. Another interviewee pointed out that she used the smart phone everyday both in and out of the classroom, but she never knew that the gadget the game player might become a wonderful assistance in learning English. However, two of the participants revealed a negative attitude on the experiment. Based on a careful observation in class, the researcher found that these students were extremely less confident and experienced on independent on-line study because they were used to instructions of a teacher in the traditional classroom. They felt anxious when confronted with vast learning materials on the internet, let alone conducting effective online study. Once they were behind the schedule online, they 
had problems involving in the class-activities in the face-to-face meeting. Hence, the proposed blended still has a room to be improved in the future study in that the teacher need encourage students to collaborate closely with their peers and kept journal for their collaborative learning. Teachers need to watch the students' independent online study carefully and ready to offer strategic help when they are in need.

\section{Conclusion}

The present study contributes to the development of blended learning by implementing the blended model in content-based EFL curriculum to improve the learners' listening and speaking proficiencies. The results of the evaluation confirm that the proposed model is effective and learners satisfied with it. This research enriches the theory of blended learning and CBI by integrating the two instructions into a new approach and implementing it on EFL curriculum. In addition, the present research also made full use of the latest technologies and tools to assist on-line learning which allowed the students to learn anytime and anywhere with handy tools like smartphones and pad. Compared with traditional classroom and early blended learning model, the flexibility of mobile learning and the vast theme-based learning materials online stimulated the motivation and interest of the students and could be helpful to construct their independent learning strategies. This integrated instructional model can be implemented in any foreign language learning and any domain of foreign language learning. In the future research the model will be used to improve blended learning in different content-based EFL curricula, such as writing and translation.

\section{Acknowledgement}

This work is supported by the 12th Five-Year Plan Project of Education Science in Liaoning Province (JG15DB418).

\section{$9 \quad$ References}

[1] D. M. Brinton, and P. E. Master, New Ways in Content-Based Instruction. New Ways in TESOL Series II. Innovative Classroom Techniques, TESOL, 1997.

[2] D. R. Garrison, T. Anderson, and R. Garrison, E-Learning in the 21st Century: A Framework for Research and Practice, Routledge, 2011.

[3] K. Olapiriyakul, and J. M. Scher, "A guide to establishing hybrid learning courses: Employing information technology to create a new learning experience, and a case study," Internet \& Higher Education, vol.9, no.4, pp.287-301, 2006. https://doi.org/10.101 6/j.iheduc.2006.08.001

[4] L.M. Bullock, R. A. Gable, and J. D. Mohr, "Technology-Mediated Instruction in Distance Education and Teacher Preparation in Special Education," Teacher Education \& Special Education the Journal of the Teacher Education Division of the Council for Exceptional Children, vol.31, no.31, pp.229-242, 2008. https://doi.org/10.1177/0888406408330644 
[5] D. W. Sanders, and A. I. Morrisonshetlar, "Student Attitudes toward Web-Enhanced Instruction in an Introductory Biology Course," Journal of Research on Computing in Education, vol.33, no.3, pp,251-262, 2014.

[6] E. Y. Huang, S. W. Lin, and T. K. Huang, "What type of learning style leads to online participation in the mixed-mode e-learning environment? A study of software usage instruction," Computers \& Education, vol.58, no.1, pp.338-349, 2012. https://doi.org/10.10 16/j.compedu.2011.08.003

[7] C. J. Bonk, and C. R. Graham, The handbook of blended learning, 2006.

[8] N. Hoic-Bozic, M. H. Dlab, and V. Mornar, "Recommender System and Web 2.0 Tools to Enhance a Blended Learning Model," IEEE Transactions on Education, vol.59, no.1, pp.39-44, 2015. https://doi.org/10.1109/TE.2015.2427116

[9] Singh H, Reed C. A White Paper: Achieving Success with Blended Learning [J]. Centra Software Retrieved, 2001, 12(March):206-207.

[10] Stoller, Fredricka L. "Methodology in Language Teaching: Project Work: A Means to Promote Language and Content." English Teachers' Journal, vol. 54, 2002, pp. 9-17.

[11] L. F. Stoller, "Content-Based Instruction," Encyclopedia of language and education, Springer US, pp.1163-1174, 2008, pp.59. https://doi.org/10.1007/978-0-387-30424-3_89

[12] Swain M, Lapkin S. Evaluating Bilingual Education: A Canadian Case Study. Multilingual Matters 2.[M]. Multilingual Matters Ltd. Bank House, 8A Hill Road, Clevedon, Avon ES21 7HH, England (paperback, ISBN-0-905028-09-0, 3.90 pounds; hardback, ISBN-0905028-10-4, 8.90 pounds). 1982.

[13] Owston R D, Garrison D R, Cook K. Blended learning at Canadian universities: Issues and practices [J]. Higher Education Academy, 2006.

[14] Gilbert N J, Driscoll M P. Collaborative Knowledge Building: A Case Study[J]. Educational Technology Research \& Development, 2002, 50(1):59-79. https://doi.org/10.1 007/BF02504961

[15] Creswell J W. Qualitative inquiry and research design:, Choosing among five traditions.[J]. Sage Publications, 1998, 16(4):473-5.

[16] F. L. Stoller, and W. Grabe, "A six-T's approach to content-based instruction," The content-based classroom: Perspectives on integrating language and content, pp.78-94, 1997.

[17] Rutter M. Proceeding from Observed Correlation to Causal Inference: The Use of Natural Experiments. [J]. Perspectives on Psychological Science, 2010, 2(4):377-395. https://doi.org/10.1111/j.1745-6916.2007.00050.x

\section{Authors}

Wen $Y \mathbf{u}$ is a lecturer of English Department, School of Social Science, English and Physical Education, Shenyang Pharmaceutical University, No.103 Wenhua Street, Shenyang, Liaoning Province, China, 110016. Her main research interests include applied linguistics, EFL pedagogy, and smart learning.

Xiaozhou Du is an engineer of Information and Communication Engineering Design Institute, Shayang Street, Shenyang, Liaoning Province, China, 110000. His main research interests include cyber physical systems and smart learning environment.

Article submitted 2018-03-08. Resubmitted 2018-10-30. Final acceptance 2018-11-18. Final version published as submitted by the authors. 